\title{
BRIEF
}

\section{The Myth of Multitasking and What It Means for Future Pharmacists}

\author{
Stephanie Enz, PharmD, ${ }^{\mathrm{a}}$ Amanda C. G. Hall, PhD, ${ }^{\mathrm{b}}$ Kathryn Keirn Williams, PharmD $^{\mathrm{c}}$ \\ ${ }^{\text {a }}$ Butler University, College of Pharmacy \& Health Sciences, Indianapolis, Indiana \\ ${ }^{\mathrm{b}}$ Butler University, College of Liberal Arts \& Sciences, Indianapolis, Indiana \\ ${ }^{\mathrm{c}}$ Eli Lilly and Company, Indianapolis, Indiana
}

Corresponding Author: Stephanie Enz, Butler University College of Pharmacy \& Health Sciences, 4600 Sunset Avenue, Indianapolis, IN 46208. Tel: 317-294-8448. Email: senz@butler.edu

Submitted July 1, 2020; accepted March 30, 2021; ePublished April 2021

Objective. The primary purposes of this study were to: 1) determine the extent to which multitasking affects the speed and accuracy with which professional-phase pharmacy students identify prescription errors and 2) determine if there is a relationship between students' self-perception of their multitasking ability and their actual ability.

Methods. 121 second-year pharmacy students enrolled in Introduction to Dosage Forms spent one week in the experimental (multitasking) condition and one week in the control (undistracted) condition. Subjects were given 10 minutes to check 10 prescriptions and record any identified filling errors. A cellular phone was placed in each room. Subjects in the experimental (multitasking) condition answered a call from a researcher posing as a chatty customer during the prescription-checking task; those in the control condition were not interrupted by a cell phone call during the task. Subjects' completion times and accuracy were recorded.

Results. When subjects where multitasking, they took significantly longer to complete the prescription-checking task than when they were not multitasking. Furthermore, when subjects were multitasking, they scored significantly lower on the prescription-checking task than when they were not multitasking. Finally, students' self-perceptions of their multitasking abilities were not related to the speed with which they completed the prescription-checking task nor to their accuracy. Conclusion. Multitasking negatively affects speed and accuracy of prescription verification in student pharmacists. Our procedure can be used as an in-class activity to demonstrate attentional limitations and to shape how future pharmacists practice.

Keywords: multitasking, distractions, sterile cockpit, cellular phone use

\section{INTRODUCTION}

In his book, CrazyBusy, Edward Hallowell states that "multitasking is a mythical activity" and, even 2000 years ago, Publius Syrius knew "to do two things at once is to do neither." A visit to any college campus will provide many opportunities to witness young people using their cell phones while reading, studying, and attending lecture, even though there is a wealth of research showing that learning, memory, and cognitive efficiency suffer when attention is divided during multitasking. ${ }^{2-10}$

In the clinical setting, cellular phones are used to prescribe, consult, monitor, and access drug and disease information, but cell phone use can be distracting. In one specific case, a patient undergoing an AV node ablation procedure died because the anesthesiologist, who was texting and posting on Facebook, did not notice the patient's falling blood oxygen level. ${ }^{11,12}$

For many healthcare professionals, distractions and interruptions are part of daily life; they draw attention from the primary task and often lead to behaviors that contribute to medication errors. ${ }^{13-16}$ Although research on interruptions in a pharmacy setting is limited, Flynn and colleagues showed a significant relationship between distractions in a pharmacy and medication dispensing errors. ${ }^{17}$ Pharmacists do recognize that distractions and interruptions can increase the likelihood of medication errors. ${ }^{18-21}$ However, when faced with high-volume performance expectations and being rewarded for speed over accuracy, they resort to multitasking behaviors when, in reality, multitasking actually decreases efficiency. ${ }^{22}$

\section{Objectives}

The primary goal of our study was to determine the extent to which multitasking affects accuracy and efficiency in identifying prescription-processing errors. We hypothesized that engaging in multitasking behavior would result in a 
decrease in accuracy and efficiency. Our secondary goal was to compare (and to determine if there is a relationship between) students' self-perception of their multitasking ability and their actual ability.

\section{METHODS}

This study used a one-way repeated measures design with experimental and control conditions to compare subjects' accuracy and efficiency in a simulated prescription-checking exercise. Each subject completed the exercise two times - once without distraction (control) and once while attempting to multitask (experimental) - in a counterbalanced design to control for order effects.

Subjects were 121 second-year professional pharmacy students, enrolled in a skills-based laboratory course. The study was introduced at the beginning of the semester and all students submitted an informed consent. Once enrolled, subjects categorized their own multitasking ability as below average, average, or above average.

To create experimental materials, the researchers "filled" 20 prescriptions, 10 used in control sessions and 10 in multitasking sessions. Errors were intentionally incorporated into seven of the 10 prescriptions for each session. The errors in both sets were similar in nature and included wrong patient, drug, strength, or directions. Each prescription was placed in a basket with a hard copy of the prescription, the stock bottle, and a labeled vial containing the medication. Subjects marked each prescription as error-free or they recorded any identified errors. Subjects were given 10 minutes to complete the task. A timer was placed in the room so they could gauge their own progress.

During both the control and experimental conditions, a cellular phone was placed in the prescription checking area. Subjects were told to answer the phone if it rang and to engage in conversation while they continued checking the prescriptions. In the control setting, subjects completed their task without distraction. In the experimental setting, a coinvestigator, playing the role of a "chatty" customer, called the subject at the one-minute mark. The same script was used for all calls and was designed to keep subjects distracted from their primary task for eight minutes (excerpt: "Do you think you could go out and grab me a travel toothbrush and toothpaste so I can just swing through the drive-thru window when I come by to pick up my prescriptions?").

If subjects completed the task before the time expired, they were told to end the phone call and leave the room. If time expired before the task was completed, investigators recorded subjects' time to completion as 10 minutes as well as the number of unchecked prescriptions. All results were de-identified and students were not assigned a grade for this activity.

Immediately following the experimental session, each subject was asked three questions related to the conversation (eg, What items did the person on the phone ask you to get for them?). If the subject was not able to answer at least two of the three questions correctly, they were excluded from the study due to their lack of engagement in the conversation.

The design and implementation of this activity required allocation of time and funds. The time to prepare the materials and script was approximately four hours. The total time to have each student complete both the control and experimental sessions was 80 hours. This course utilizes upperclassmen as laboratory assistants (salary $\$ 8 /$ hour) who assisted in the flow of the activity.

IBM SPSS statistical program (v24, 2016) was used for data analysis. All tests were non-directional, using a .05 alpha level of significance. Analyses of variance ( $F$-tests) were used to evaluate group mean differences.

\section{RESULTS}

There were 129 students (30\% identified as male and 70\% identified as female) who participated in this study (eight participants' data were omitted due to lack of engagement in the phone conversation). Twenty (17\%) believed themselves to be below average multitaskers, $84(69 \%)$ described themselves as average, and 17 (14\%) categorized themselves as above average. A chi-square analysis revealed no gender differences in self-ratings of multitasking, $\chi^{2}(2)$ $\geq 3.31, p=.19$.

To determine the effects of multitasking on task completion time and on prescription-checking accuracy, we conducted a two-way repeated-measures analysis of variance with Condition (multitasking vs. control) and Measure (time vs. score) as factors. Results revealed that, when they were multitasking, subjects took an average of $23 \%$ longer to complete the task $(\mathrm{M}=7.5 \mathrm{~min}, \mathrm{SD}=1.9)$ than when they were not multitasking $(\mathrm{M}=6.1 \mathrm{~min}, \mathrm{SD}=1.7), \mathrm{F}(1,120)=2129.66$, Wilks' $\lambda=.05, p<.001$, partial $\eta^{2}=.95$. This analysis also revealed that, when they were not multitasking subjects scored $26 \%$ better on the prescription-checking task $(\mathrm{M}=8.5, \mathrm{SD}=1.4)$ than when they were multitasking $(\mathrm{M}=6.7, \mathrm{SD}=1.7), \mathrm{F}(1$, $120)=71.13$, Wilks' $\lambda=.63, p<.001$, partial $\eta^{2}=.37$. Finally, the Condition $x$ Measure interaction was significant, as accuracy was higher in the control condition and times were higher in the multitasking condition, $F(1,120)=76.30$, Wilks' $\lambda=.61, p<.001$, partial $\eta^{2}=.38$. 
To determine the relationship between self-perception of multitasking and task-completion time, we conducted a one-way between-groups analysis of variance with self-perception of multitasking category (below average, average, or above average) as the independent variable and difference between the task completion times while multitasking and while not distracted as the dependent variable. Table 1 presents mean task completion times and accuracy scores as a function of multitasking self-rating and Condition. The analysis revealed no significant difference between self-rating groups, $F(2,118)=0.92, M S E=202.18, p=.40$. Therefore, subjects' self-perceptions of their multitasking abilities were not related to their speed in completing the task. Furthermore, a one-way analysis of variance with self-perception of multitasking category (below average, average, or above average) as the independent variable and difference between prescription-checking accuracy score while multitasking and while not distracted as the dependent variable revealed no relationship between self-rating of multitasking and the effect of multitasking on prescription-checking accuracy, $F(1$, 118)=0.32, $M S E=4.29, p=.724$. Therefore, students' self-perceptions of their multitasking abilities were not related to the accuracy with which they completed the prescription-checking task.

\section{DISCUSSION}

The primary purpose of our study was to determine to what extent multitasking affects accuracy and efficiency in identifying prescription-processing errors. Consistent with the findings of Sinclair and colleagues, we found that multitasking during prescription checking resulted in decreased efficiency. ${ }^{22}$ Although there is limited published research on the association between pharmacists' multitasking behaviors and their error rates, there is empirical evidence of a relationship between distractions and errors made while checking prescriptions. ${ }^{17}$ Our results are consistent with this finding and provide stronger evidence of a causal link, as we experimentally manipulated the presence of distraction.

One additional consideration in the study of multitasking ability is the extent to which individuals believe themselves to be proficient at multitasking. A study by Sanbonmatsu et al. suggests that people tend to overestimate their ability to multitask. ${ }^{23}$ Ophir found that people who think they are the most capable multitaskers are actually the least capable, yet they are the most likely to engage in multitasking behavior. ${ }^{24}$ Although we did not find a similar inverse relationship between self-perception and performance, our study could be expanded to include a post-intervention survey to determine if students' self-assessment of their own multitasking ability can be adjusted by the implementation of this exercise.

As noted in the Methods section, subjects were halted if they had not completed the task after 10 minutes. Although we do not have exact completion times for subjects who did not complete all 10 prescriptions during this time, we expect that, if they had been permitted to work to completion, the time difference between experimental and control conditions would have been even greater. This prediction is based on our finding that a larger percentage of subjects did not complete the task within 10 minutes when they were in the experimental condition (17\%) than when they were in the control condition (2\%). Furthermore, participants had more incomplete (i.e., unchecked) prescriptions when they were in the experimental condition $(M=0.35, S D=0.92)$ than when in the control condition $(M=0.03, S D=-.22), t(120)=3.64$, $p<.001$.

Future research could assess the extent to which students found the demonstration to be impactful, as we revealed students' results to them but did not assess their impressions of the activity. Additional multitasking research could investigate other common sources of distraction within a pharmacy setting and their impact on accuracy and efficiency. Similarly, future research could compare multitasking abilities of pharmacy students to those of practicing pharmacists to determine whether experience and familiarity with setting affect accuracy and/or efficiency.

Strategies that are being taught in medical and nursing schools for navigating interruptions and distractions can easily be translated into a pharmacy setting. ${ }^{25-27}$ One design intervention is called the sterile cockpit, a reference to the federal regulation that allows pilots to focus on critical phases of flight without distraction. ${ }^{28}$ In a pharmacy, a sterile cockpit or No Interruption Zone (NIZ) is a designated area in which a pharmacist can perform duties that require focused attention. Implementation of a NIZ for nurses' medication administration resulted in a $40 \%$ decrease in interruptions. ${ }^{29}$ Attri et al recommend a sterile cockpit rule to eliminate cell phone distraction during critical phases of surgeries. ${ }^{30}$ One important aspect of the NIZ is the use of a visual cue to indicate a request for the attention of the person working in the NIZ. This creates a boundary that allows the person to complete one primary task before diverting their attention elsewhere. When interruptions can occur at a boundary between tasks in this manner, one study showed error rates decrease by $50 \% .^{31}$

\section{CONCLUSION}

The Agency for Healthcare Research and Quality states that distractions in healthcare are "threats to human performance and safety." 25 In a pharmacy setting, engaging in multitasking behavior can result in medication errors and 
patient harm. The ability to identify medication safety issues is one the Entrustable Professional Activities expected of all pharmacy graduates. ${ }^{32}$ It is our responsibility as educators to ensure our graduates understand that attempting to multitask is cognitively taxing and can result in decreased efficiency and an increased rate of errors. We also need to provide them the tools necessary to design a system that minimizes unsafe multitasking behaviors.

\section{ACKNOWLEDGMENT}

The authors would like to thank Dr. Margaret Stratford for her assistance with data management.

\section{REFERENCES}

1. Hallowell EM. CrazyBusy. New York, NY:Random House Publishing; 2007.

2. Konig CJ, Buhner M, Murling F. Working memory, fluid intelligence, and attention are predictors of multitasking performance, but polychronicity and extraversion are not. Hum Perform. 2005;18:243-266. doi:10.1207/s15327043hup1803_3

3. Navon D, Gopher D. On the economy of the human processing systems. Psychol Rev. 1979;86:214-255. doi:10.1037/0033-295X.86.3.214

4. Pashler H. Dual-task interference in simple tasks: data and theory. Psychol Bull. 1994;116:220-244. doi:10.1037/0033-2909.116.2.220

5. Posner M. Cumulative development of attentional theory. Am Psychol. 1982;37:168-179. doi:10.1037/0003066X.37.2.168

6. Wickens CD. Multiple resources and performance prediction. Theor Issues Ergon Sci. 2002;3:159-177. doi:10.1080/14639220210123806

7. Broadbent D. Perception and communication. Oxford, England: Pergamon Press; 1958.

8. Rubinstein JS, Meyer DE, Evans JE. Executive control of cognitive processes in task switching. $J$ Exp Psychol. 2001;27(4):763-797. doi:10.1037//0096-1523.27.4.763

9. Tulving E, Thomson DM. Encoding specificity and retrieval processes in episodic memory. Psychol Rev. 1973;50:352-373. doi:10.1037/h0020071

10. Rothbart MK, Posner MI. The developing brain in a multitasking world. Dev Rev. 2015;35:42-63. doi:10.1016/j.dr.2014.12.006

11. Ventola CL. Mobile devices and apps for health care professionals: uses and benefits. P T. 2014;39(5):356-364.

12. Hawryluk M. Is your surgeon focused on you or his smartphone? The Bulletin. https://www.bendbulletin.com/localstate/is-your-surgeon-focused-on-you-or-his-smartphone/article_340cc2ae-e5bb5123-86ec-1e2389537497.html. February 1, 2015. Accessed March 23, 2021.

13. Chisholm CD, Collison EK, Nelson DR, Cordell WH. Emergency department workplace interruptions: are emergency physicians "interrupt-driven" and "multitasking"? AEM Educ Train. 2008;8(11):1239-1243. doi:10.1111/j.15532712.2000.tb00469.x

14. Campbell G, Arfanis K, Smith AF. Distraction and interruption in anaesthetic practice. Br J Anaesth. 2012;109(5):707-715. doi:10.1093/bja/aes219

15. Guerin A. Before-and-after study of interruptions in a pharmacy department. Can J Hosp Pharm. 2013;66(1):8-12. doi:10.4212\%2Fcjhp.v66i1.1206

16. Santell JP, Hicks RW, McMeekin J, Cousins D. Medication errors: experience of the United States Pharmacopeia (USP) MEDMARX reporting system. J Clin Pharmacol. 2003;43:760-767. doi:10.1177/0091270003254831

17. Flynn EA, Barker KN, Gibson JT, Pearson RE, Berger BA, Smith LA. Impact of interruptions and distractions on dispensing errors in an ambulatory care pharmacy. Am J Health Syst Pharm. 1999;56:1319-1325. doi:10.1093/ajhp/56.13.1319

18. Beso A, Franklin BD, Barber N. The frequency and potential causes of dispensing errors in a hospital pharmacy. Int $J$ Clin Pharm. 2005;27(3):182-190. doi:10.1007/s11096-004-2270-8

19. Petersen GM, Wu MSH, Bergin JK. Pharmacists' attitudes towards dispensing errors: their causes and prevention. $J$ Clin Pharm Ther. 1999;24:57-71. doi:10.1046/j.1365-2710.1999.00199.x

20. James KL, Barlow D, McArtney R, Hiom S, Roberts D, Whittlesea C. Incidence, type and causes of dispensing errors: a review of the literature. Int J Pharm Pract. 2009;17:9-30. doi:10.1211/ijpp/17.1.0004

21. Holden RJ, Patel NR, Scanlon MC, Shalaby TM, Arnold JM, Karsh BT. Effects of mental demands during dispensing on perceived medication safety and employee well-being: a study of workload in pediatric hospital pharmacies. Res Social Adm Pharm. 2010;6(4):293-306. doi:10.1016/j.sapharm.2009.10.001 
22. Sinclair A, Slimm M, Terry D. To investigate how disruptive interruptions are on paediatric dispensary accuracy checkers. Arch Dis Child. 2012;97:e1-21.

23. Sanbonmatsu DM, Strayer DL, Medeiros-Ward N, Watson JM. Who multi-tasks and why? Multi-tasking ability, perceived multi-tasking ability, impulsivity, and sensation seeking. PLoS ONE. 2013;8(1):e54402. https://journals.plos.org/plosone/article?id=10.1371/journal.pone.0054402. January 23, 3013. Accessed March 23, 2021.

24. Ophir E, Nass C, Wagner AD. Cognitive control in media multitaskers. Proc Natl Acad Sci U S A. 2009;106(37):15583-15587. doi:10.1073/pnas.0903620106

25. Beyea S. Interruptions and distractions in health care: improved safety with mindfulness. Agency for Healthcare Research and Quality Patient Safety Network. https://psnet.ahrq.gov/perspective/interruptions-and-distractions-healthcare-improved-safety-mindfulness. February 1, 2014. Accessed March 23, 2021.

26. Skaugset LM, Farrell S, Carney M, et al. Can you multitask? Evidence and limitations of task switching and multitasking in emergency medicine. Ann Emerg Med. 2016;68(2):189-195. doi:10.1016/j.annemergmed.2015.10.003

27. Heng KW. Teaching and evaluating multitasking ability in emergency medicine residents - what is the best practice? Int J Emerg Med. 2014;7:41. doi:10.1186/s12245-014-0041-4

28. Code of Federal Regulations. Title 14 aeronautics and space, Part 121 operating requirements: domestic, flag, and supplemental operations. Subpart T flight operations, Section 121.542 flight crewmember duties. https://www.ecfr.gov/cgi-bin/text-idx?tpl=/ecfrbrowse/Title14/14tab_02.tpl Accessed March 23, 2021.

29. Anthony K, Wiencek C, Bauer C, Daly B, Anthony MK. No interruptions please: impact of a no interruption zone on medication safety in intensive care units. Crit Care Nurse. 2010;30(3):21-29. doi:10.4037/ccn2010473

30. Attri JP, Khetarpal R, Chatrath V, Kaur J. Concerns about usage of smartphones in operating room and critical care scenario. Saudi J Anaesth. 2016;10(1):87-94. doi:10.4103/1658-354X.169483

31. Bailey BP, Konstan JA. On the need for attention-aware systems: measuring effects of interruption on task performance, error rate, and affective state. Comput Human Behav. 2016;22(4):685-708. doi:10.1016/j.chb.2005.12.009

32. Haines ST, Pittenger AL, Stolte SK, et al. Core entrustable professional activities for new pharmacy graduates. Am J Pharm Educ. 2017;81(1):S2. doi:10.5688/ajpe811S2 
Table 1. Task Completion Times (in Minutes) and Accuracy Scores as a Function of Multitasking SelfRatings and Condition (Multitasking vs. Control)

\begin{tabular}{ccccccc}
\hline & \multicolumn{2}{c}{ Below Average $(\boldsymbol{n}=\mathbf{2 0})$} & \multicolumn{2}{c}{ Average $(\boldsymbol{n}=\mathbf{8 4})$} & \multicolumn{2}{c}{ Above Average $(\boldsymbol{n}=\mathbf{1 7})$} \\
\cline { 2 - 7 } & Multitasking & Control & Multitasking & Control & Multitasking & Control \\
\cline { 2 - 7 } & $\mathbf{M}($ SD) & $\mathbf{M}($ SD) & M (SD) & M (SD) & M (SD) & M (SD) \\
\hline Time & $8.02(1.83)$ & $6.14(1.86)$ & $7.51(1.96)$ & $6.11(1.69)$ & $6.78(1.94)$ & $5.72(1.69)$ \\
Score & $6.75(1.80)$ & $8.30(1.08)$ & $6.60(1.75)$ & $8.46(1.36)$ & $7.35(1.17)$ & $8.88(1.93)$ \\
\hline
\end{tabular}

